\title{
The role of thiol levels in predicting contrast-induced nephropathy in patients with ST-segment elevation myocardial infarction who underwent primary percutaneous coronary intervention
}

\author{
(1) Ahmet Korkmaz, ${ }^{1}$ (1) Burcu Ozyazgan, ${ }^{1}$ 연 Arzu Kosem, ${ }^{2}$ (1) Ozgul Ucar Elalmis, ${ }^{1}$ (i) Umit Guray, ${ }^{1}$ \\ Mehmet Ileri, ${ }^{1}$ (D) Salim Neselioglu, ${ }^{3}$ (D) Ozcan Erel $^{3}$ \\ ${ }^{1}$ Department of Cardiology, Ankara Numune Training and Research Hospital, Ankara, Turkey \\ ${ }^{2}$ Department of Clinical Biochemistry, Ankara Numune Training and Research Hospital, Ankara, Turkey \\ ${ }^{3}$ Department of Clinical Biochemistry, Yildirim Beyazit University Faculty of Medicine, Ankara, Turkey
}

\begin{abstract}
OBJECTIVE: Contrast-induced nephropathy (CIN) is a common complication of diagnostic or interventional procedures that may arise from administration of intravascular contrast media. Recent studies have reported the thiol-disulfide ratio as a novel oxidative stress marker. Therefore, we investigated the role of thiol levels in predicting CIN in patients with ST-segment elevation myocardial infarction (STEMI) who had undergone primary percutaneous coronary intervention (PCI).

METHODS: A total of 302 patients were enrolled in the study. CIN was defined as an increase in serum creatinine concentration $\geq 0.5 \mathrm{mg} / \mathrm{dL}$ compared with the admission value or a $>25 \%$ relative rise during the first $48-72$ hours after the procedure. To evaluate the relationship between thiol levels and CIN, the patients were divided into a CIN group and a non-CIN group. RESULTS: CIN occurred in $44(15 \%)$ patients. Native thiol $(274.8 \pm 84.7 \mu \mathrm{mol} / \mathrm{L}$ vs. $220.8 \pm 97.1 \mu \mathrm{mol} / \mathrm{L}, \mathrm{p}=0.001)$ and total thiol $(305.4 \pm 89.7 \mu \mathrm{mol} / \mathrm{L}$ vs. $260.1 \pm 102.1 \mu \mathrm{mol} / \mathrm{L}, \mathrm{p}=0.009)$ levels were higher in patients within the non-CIN group. Disulfide $(15.8 \pm 6.6 \mu \mathrm{mol} / \mathrm{L}$ vs. $19.6 \pm 8.4 \mu \mathrm{mol} / \mathrm{L}, \mathrm{p}=0.002)$ levels, and mean disulfide/total thiol ratios $(8.4 \pm 3.7 \mathrm{vs} .5 .9 \pm 3.1$, $\mathrm{p}=0.001$ ) were higher in patients with CIN (+) group. In univariate analysis, the initial native thiol, total thiol, disulfide levels, and disulfide/total thiol ratio were found to have prognostic significance in the development of CIN. In the multivariate regression analysis, only the disulfide/total thiol ratio (OR=1.190; $95 \% \mathrm{CI}: 1.090-1.300 ; p=0.001)$ was significantly and independently associated with CIN. The cutoff value of the disulfide/total thiol ratio to predict CIN on admission in patients with STEMI who underwent primary PCI was 7, with a sensitivity of $68.2 \%$ and a specificity of $79.8 \%$.
\end{abstract}

CONCLUSION: Our results suggest that thiol/disulfide homeostasis could be a good biochemical risk marker for CIN in STEMI patients who underwent primary PCI.

Keywords: Acute myocardial infarction; contrast-induced nephropathy; thiol levels.

Cite this article as: Korkmaz A, Ozyazgan B, Kosem A, Ucar Elalmis O, Guray U, Ileri M, et al. The role of thiol levels in predicting contrast-induced nephropathy in patients with ST-segment elevation myocardial infarction who underwent primary percutaneous coronary intervention. North Clin Istanb 2019;6(3):210-218.

Received: December 27, 2017 Accepted: September 24, 2018 Online: August 26, 2019

Correspondence: Dr. Ahmet KORKMAZ. Ankara Numune Egitim ve Arastirma Hastanesi, Kardiyoloji Klinigi, Ankara, Turkey. Tel: +90 5059135380 e-mail: drahmtkrkmz07@gmail.com

(c) Copyright 2019 by Istanbul Provincial Directorate of Health - Available online at www.northclinist.com 
$\mathrm{C}$ ontrast-induced nephropathy (CIN) is a common complication of diagnostic or interventional procedures that may arise from administration of intravascular contrast media. It is defined as an increase in baseline serum creatinine level by $\geq 25 \%$ or an absolute increase of $\geq 0.5$ $\mathrm{mg} / \mathrm{dL}$ within 48-72 hours after contrast media administration [1]. CIN has become the third leading cause of hospital-acquired acute kidney injury following surgery and nephrotoxic drug damage, accounting for $11 \%$ of observed cases [2]. The reported incidence of CIN ranges between $5 \%-50 \%$ depending on the previous risk of the investigated patient population [3]. Pre-existing renal dysfunction and diabetes mellitus (DM) are major patient-related risk factors [3]. CIN is closely associated with prolonged hospitalization, increased costs, a risk of end-stage renal failure, repeated revascularization, and increased morbidity and mortality in the short- and long-term $[1,4,5]$.

Thiols are organosulfuric compounds that contain carbon-bonded sulfhydryl groups (-SH). They are mostly present in the cytosol and mitochondria [6], with lower concentrations in plasma. They are composed of human plasma albumin and to a lesser extent by low-molecular-weight thiols such as cysteinylglycine, cysteine (Cys), homocysteine, glutathione, and $\gamma$-glutamylcysteine [7]. Thiols may undergo oxidative reactions that yield various products. One such process is the thiol-disulfide exchange reaction [8]. When oxidative stress increases, oxidation of Cys residues lead to the reversible formation of mixed disulfides between low-molecular-mass thiols and protein thiol groups. These disulfide bonds can be reduced back to thiol groups, thus maintaining a thiol/ disulfide homeostasis [9]. Therefore, thiols constitute a substantial proportion of the total level of antioxidants and play an important role in the defense mechanisms against radical oxygen species (ROS) [10].

In recent studies, the thiol-disulfide ratio has been reported to be a novel oxidative stress marker. Although there is a confirmed association of oxidative stress with acute myocardial infarction (AMI) and CIN [11-14], to our knowledge, there are no studies to date that address thiol levels and thiol/disulfide homeostasis in CIN. Therefore, we investigated the role of thiol levels in predicting CIN in patients with ST-segment elevation myocardial infarction (STEMI) who underwent primary percutaneous coronary intervention (PCI).

\section{MATERIALS AND METHODS}

The Local Ethics Committee approved of the study protocol and all participants provided their written informed consents. From November 2016 to September 2017, we prospectively collected in-hospital data from consecutive patients who underwent emergency primary PCI for AMI within 12 hours of the onset of symptoms. The diagnosis of STEMI was established according to contemporary guidelines [15]. We excluded patients who were on chronic peritoneal or hemodialysis treatment, those who had undergone renal transplantation, or those who had been exposed to a contrast injection within 2 weeks before PCI. Patients with an active infection or chronic inflammatory disease, a significant systemic disease, severe hepatic dysfunction, known malignancy, or major surgery in the previous month were also excluded, as were patients who presented with cardiogenic shock or died during the first 72 hours of their hospital stay or during revascularization. During the study, 302 patients who met the above-mentioned criteria were enrolled. To evaluate the possible relationship between thiol levels and CIN, the study patients were divided into two groups according to the development of CIN, i.e., CIN (+) group and CIN (-) group.

The patients' baseline characteristics were recorded along with their respective in-hospital and followup data. In all patients, a detailed medical history was recorded, including the presence and management of hypertension, hypercholesterolemia, diabetes mellitus, family history of coronary artery disease, and smoking status. Patients who had an average blood pressure level of $\geq 140 / 90 \mathrm{mmHg}$ or were under antihypertensive medication were considered hypertensive. DM was diagnosed if the patient had fasting glucose levels of $\geq 126$ $\mathrm{mg} / \mathrm{dl}$ measured twice during the follow-up or was on an antidiabetic prescription before the AMI incident [16]. Patients who smoked at least one cigarette per day were deemed active smokers.

All primary PCIs were performed via the femoral or radial artery by an experienced interventional cardiologist using the appropriate equipment (Siemens Axiom Artis Z Angiography System, Germany). Nonionic low osmolality contrast medium (Omnipaque 350 $\mathrm{MG} / \mathrm{ml}$; GE Healthcare, Cork, Ireland) was used for these procedures. Total contrast medium volume used during primary PCI was recorded in all patients. All patients were administered $300 \mathrm{mg}$ acetylsalicylic acid (ASA) with a loading dose of $60 \mathrm{mg}$ prasugrel or 180 mg ticagrelor before the procedure. A dose of 70-100 $\mathrm{U} / \mathrm{kg}$ unfractionated heparin was administered after 
visualizing the arterial anatomy. The use of bare metal or drug-eluting stents and glycoprotein IIb/IIIa was left to the discretion of the physician. All patients received intravenous hydration with isotonic saline. All patients were transferred to the intensive care unit after the procedure, where treatment was continued with $100 \mathrm{mg} \mathrm{ASA}$ and $10 \mathrm{mg}$ prasugrel or $90 \mathrm{mg}$ ticagrelor twice a day. The decision for concurrent use of statins, angiotensin-converting enzyme inhibitors, and beta-blockers was made according to the recommendations in the guidelines. After the coronary intervention, transthoracic echocardiography assessments were performed at the coronary intensive care unit using Vivid 7 (GE Medical System, Horten, Norway) with a 3.5 $\mathrm{MHz}$ transducer.

On admission, venous blood samples were obtained before the administration of any medication. Serum creatinine concentration was measured in all patients at admission and at 24 hours, 48 hours, and 72 hours after primary PCI. After the serum samples for thiol were collected, they were centrifuged at $1500 \mathrm{~g}$ for 10 minutes and the separated samples were stored in plain tubes at $-800 \mathrm{C}$ until the analysis. CIN was defined as an increase in serum creatinine concentration by $\geq 0.5$ $\mathrm{mg} / \mathrm{dL}$ as compared to the admission value or a $>25 \%$ relative rise during the first 48-72 hours after the procedure. Serum glucose, creatinine, blood urea nitrogen, alanine-amino transferase, total cholesterol, low-density lipoprotein (calculated with Friedewald Formula: Total cholesterol-(HDLc)-TG/5), high-density lipoprotein, and triglyceride values were measured by an automatic biochemistry analyzer (Roche Diagnostics, Indianapolis, IN, USA). Hematological parameters were measured from citrate-based anticoagulated tubes by the Sysmex K-1000 autoanalyzer (Block Scientific, Bohemia, N.Y., USA) within 30 minutes of sampling.

Thiol/disulfide homeostasis was measured according to the procedure defined by Erel et al. [17]. Subsequently, the reducible disulfide bonds were reduced to form free functional thiol groups. Sodium borohydride was used as reductant the and unused reductant was extracted with formaldehyde. All thiol groups containing native and reduced bonds were determined after a reaction with 5, 5'-dithiobis-(2-nitrobenzoic) acid. Half of the difference between native and total thiols ensured the dynamic disulfide quantity $(-\mathrm{S}-\mathrm{S})$. After determining the amounts of native thiol $(-\mathrm{SH})$ and disulfide $(-\mathrm{S}-\mathrm{S})$, the ratio of disulfide to native thiol $(-\mathrm{S}-\mathrm{S}-/-\mathrm{SH})$ was calculated [17].

\section{Statistical Analysis}

For baseline characteristics, the Kolmogorov-Smirnov test was used to test the normality of distribution. Quantitative variables with a normal distribution were specified as mean \pm standard deviation, while variables with nonnormal distribution were shown as median (interquartile range) and categorical variables were shown as number and percentage values. For continuous variables with a normal distribution, the Student's t-test was used to compare groups, while the Mann-Whitney $U$ test was used when the distribution was not normal. Categorical variables were compared with Chi-square and Fisher's Exact Chi-square tests. To determine the independent predictors of CIN, parameters with a significance level of 0.1 or less on the univariate analysis were investigated using the univariate and multivariate logistic regression model. The receiver operating characteristics (ROC) curve was used to show the sensitivity and specificity of disulfide/total thiol ratio, which is the optimal cutoff value for predicting CIN. Differences were considered significant at the 2 -sided P-value of $<0.05$. All statistical analyses were carried out using the SPSS for Windows version 22 (IBM SPSS Inc., Chicago, IL).

\section{RESULTS}

Demographic, clinical, and laboratory characteristics of the patients are summarized in Table 1 . The study population consisted of 302 patients with a mean age of $60.2 \pm 12.7$ years. Of the 302 patients, 130 (43\%) were female and 44 (15\%) developed CIN. In the CIN group, the baseline creatinine was higher as compared to the non-CIN group. There were no differences in the other parameters between the CIN (+) and CIN (-) groups $(\mathrm{p}>0.05)$ (Table 2).

Native thiol $(274.8 \pm 84.7 \mu \mathrm{mol} / \mathrm{L}$ vs. $220.8 \pm 97.1$ $\mu \mathrm{mol} / \mathrm{L}, \mathrm{p}=0.001)$ and total thiol $(305.4 \pm 89.7 \mu \mathrm{mol} / \mathrm{L}$ vs. $260.1 \pm 102.1 \mu \mathrm{mol} / \mathrm{L}, \mathrm{p}=0.009)$ levels were higher in patients in the non-CIN group. Disulfide levels $(15.8 \pm 6.6 \mu \mathrm{mol} / \mathrm{L}$ vs. $19.6 \pm 8.4 \mu \mathrm{mol} / \mathrm{L}, \mathrm{p}=0.002)$ and mean disulfide/total thiol ratios $(8.4 \pm 3.7$ vs. $5.9 \pm 3.1$, $\mathrm{p}=0.001)$ were higher in patients with CIN $(+)$ group (Table 3). The relationship between the disulfide/total thiol ratio levels with CIN in patients with AMI is shown in Figure 1.

The results of the univariate and multivariate regression analysis for CIN are listed in Table 4. In the univariate analysis, the initial native thiol, total thiol, disulfide levels, and disulfide/total thiol ratio were found to have 
TABLE 1. Baseline clinical, demographic, and laboratory characteristics of the study population

\begin{tabular}{|c|c|c|c|}
\hline Age (Med., Mean \pm SD, Min.-Max.) & \multirow{2}{*}{\multicolumn{3}{|c|}{$\begin{array}{c}59.0 / 60.2 \pm 12.7 / 33.0-81.0 \\
172(57 \%) / 130(43 \%)\end{array}$}} \\
\hline Gender (Male / Female) & & & \\
\hline DM, n (\%) & \multicolumn{3}{|c|}{$106(35 \%)$} \\
\hline HT, n (\%) & \multicolumn{3}{|c|}{$131(43 \%)$} \\
\hline CAD, n (\%) & \multicolumn{3}{|c|}{$87(29 \%)$} \\
\hline CABG, n (\%) & \multicolumn{3}{|c|}{$32(11 \%)$} \\
\hline TIA/Stroke, n (\%) & \multicolumn{3}{|c|}{$22(7 \%)$} \\
\hline \multicolumn{4}{|l|}{ AMI localization } \\
\hline Anterior / Non-anterior & \multicolumn{3}{|c|}{$176(58 \%) / 126(42 \%)$} \\
\hline \multicolumn{4}{|l|}{ Access site } \\
\hline Femoral / Radial & \multicolumn{3}{|c|}{$184(61 \%) / 118(39 \%)$} \\
\hline \multirow[t]{2}{*}{ Smoking, n (\%) } & \multicolumn{3}{|c|}{$180(60 \%)$} \\
\hline & Median & Mean \pm SD & Min.-Max. \\
\hline Glucose (mg/dL) & 124.5 & $150.3 \pm 81.2$ & $68-533$ \\
\hline Serum creatinine (mg/dL) & 1.05 & $1.122 \pm 0.677$ & $0.63-1.8$ \\
\hline Hemoglobin (g/L) & 13.9 & $13.7 \pm 1.6$ & $9.6-16.5$ \\
\hline WBC count $\left(x 1000 / \mathrm{mm}^{3}\right)$ & 12.3 & $11.5 \pm 4.1$ & $5.8-23.7$ \\
\hline Platelet count (x1000/mm³) & 231 & $240.3 \pm 87.5$ & $110-626$ \\
\hline Total cholesterol (mg/dL) & 191 & $188.5 \pm 45.6$ & $77-387$ \\
\hline LDL (mg/dL) & 126 & $117.4 \pm 38.6$ & $51-245$ \\
\hline $\mathrm{HDL}(\mathrm{mg} / \mathrm{dL})$ & 37.6 & $39.7 \pm 10.1$ & $16-70$ \\
\hline Triglycerides (mg/dL) & 116 & $147 \pm 92$ & $35-617$ \\
\hline LVEF (\%) & 51 & $48.1 \pm 11$ & $20-64$ \\
\hline Contrast medium volume (mL) & 220 & $210.1 \pm 50.2$ & $90-400$ \\
\hline
\end{tabular}

Min.: Minimum; Max.: Maximum; SD: Standard deviation; AMI: Acute myocardial infarction; CABG: Coronary artery bypass graft; CAD: Coronary artery disease; DM: Diabetes mellitus; HDL: High-density lipoprotein; HT: Hypertension; LDL: Low-density lipoprotein; LVEF: Left ventricular ejection fraction; TIA: Transient ischemic attack; WBC: White blood cell.

prognostic significance in the development of CIN. In the multivariate regression analysis, only the disulfide/total thiol ratio $(\mathrm{OR}=1.190 ; 95 \% \mathrm{CI}=1.090-1.300 ; \mathrm{p}=0.001)$ was significantly and independently associated with CIN.

Finally, the ROC analysis was performed to determine the cutoff value of disulfide/total thiol ratio for predicting CIN. The cutoff value of disulfide/total thiol ratio on admission to predict CIN in patients with STEMI who underwent primary PCI was 7 , with a sensitivity of $68.2 \%$ and a specificity of $79.8 \%$ (AUC $=0.740(0.655-$ 0.825), p<0.001) (Fig. 2).

\section{DISCUSSION}

The primary finding of this study is that among patients with AMI who underwent primary PCI (in STEMI), the pre-procedural thiol levels that were assessed at admission served as an independent predictor of the development of post-procedural CIN. To our knowledge, this is the first study that investigated thiol/disulfide homeostasis as a novel marker for the relation between oxidative stress and CIN in patients with STEMI. Our findings demonstrated that a high level of disulfide/total thiol was significantly associated with CIN.

Thiols are important antioxidant agents in human beings. The importance of disulfide/thiol homeostasis has been shown in a number of recent studies. Kundi et al. reported that the disulfide/thiol ratio increased in AMI and they asserted that this ratio might be an indicator for detecting acute myocardial damage [13]. Topuz et al. showed that thiol/disulfide homeostasis could be altered during acute pulmonary thromboembolism and could also be associated with worsened hemodynamic parameters [18]. They also suggested that this homeostasis may be used as a prognostic marker for hospital mortality. Some studies indicate that low thiol concentrations and an imbalance in the thiol/disulfide ratio may play a pathogenic role in the formation of coronary artery ectasia (CAE), atherosclerosis, and chemotherapy-induced cardiac toxicity [19-21]. In all these studies, the authors hypothesized that oxidative stress might contribute to the main mechanism of pathogenesis. New emerging risk factors such oxidative stress, hs-CRP, N-terminal probrain natriuretic peptide, serum uric acid levels, lower bilirubin concentrations, and gamma-glutamyl transferase (GGT) were found to be relevant to CIN development [22-27]. The novel oxidative stress marker in our study, thiol/disulfide ratio, has also been linked to CIN development in patients with acute STEMI undergoing primary $\mathrm{PCI}$.

CIN represents a significant adverse event during administration of contrast medium that leads to worse clinical outcomes despite successful early coronary revascularization. The pathogenesis of CIN is complex and multifactorial and the underlying biological mechanisms have not yet been fully elucidated. Several potential factors have been postulated, such as intrarenal vasoconstriction, reduced renal blood flow, medullary hypoxia, oxidative stress, inflammation, thrombosis, endothelial dysfunction, generation of reactive oxygen species (ROS), and direct tubular epithelial cell injury by contrast media $[6,7,28]$. In certain trials, the pathophysiology of CIN appears to be based on the formation 
TABLE 2. Baseline clinical, demographic, and laboratory characteristics of patients with and without contrast-induced nephropathy

\begin{tabular}{|c|c|c|c|c|c|c|c|c|c|}
\hline & \multicolumn{4}{|c|}{ CIN (-) } & \multicolumn{4}{|c|}{$\operatorname{CIN}(+)$} & \multirow[b]{2}{*}{$\mathrm{p}$} \\
\hline & Mean \pm SD & $n$ & $\%$ & Median & Mean \pm SD & $\mathrm{n}$ & $\%$ & Median & \\
\hline Age & $60.1 \pm 12.4$ & & & 59.0 & $60.9 \pm 14.1$ & & & 58.5 & $0.724^{\mathrm{m}}$ \\
\hline \multicolumn{10}{|l|}{ Sex } \\
\hline Male & & 155 & 60 & & & 27 & 61 & & \multirow{2}{*}{$0.810^{\mathrm{x}^{2}}$} \\
\hline Female & & 103 & 40 & & & 17 & 39 & & \\
\hline \multicolumn{10}{|l|}{ DM } \\
\hline No & & 170 & 66 & & & 26 & 59 & & \multirow{2}{*}{$0.382^{x^{2}}$} \\
\hline Yes & & 88 & 34 & & & 18 & 41 & & \\
\hline \multicolumn{10}{|l|}{ HT } \\
\hline No & & 144 & 56 & & & 27 & 61 & & \multirow{2}{*}{$0.492^{x^{2}}$} \\
\hline Yes & & 114 & 44 & & & 17 & 39 & & \\
\hline \multicolumn{10}{|l|}{ Smoking } \\
\hline No & & 104 & 40 & & & 18 & 41 & & \multirow{2}{*}{$0.675^{x^{2}}$} \\
\hline Yes & & 154 & 60 & & & 26 & 59 & & \\
\hline \multicolumn{10}{|l|}{ CAD } \\
\hline No & & 185 & 72 & & & 30 & 68 & & \multirow{2}{*}{$0.633^{x^{2}}$} \\
\hline Yes & & 73 & 28 & & & 14 & 32 & & \\
\hline \multicolumn{10}{|l|}{ CABG } \\
\hline No & & 232 & 90 & & & 38 & 86 & & \multirow{2}{*}{$0.478^{x^{2}}$} \\
\hline Yes & & 26 & 10 & & & 6 & 14 & & \\
\hline \multicolumn{10}{|l|}{ TIA/Stroke } \\
\hline No & & 237 & 92 & & & 43 & 98 & & \multirow{2}{*}{$0.166^{x^{2}}$} \\
\hline Yes & & 21 & 8 & & & 1 & 2 & & \\
\hline \multicolumn{10}{|l|}{ AMI localization } \\
\hline Anterior & & 148 & 57 & & & 28 & 64 & & \multirow{2}{*}{$0.435^{x^{2}}$} \\
\hline Non-anterior & & 110 & 43 & & & 16 & 36 & & \\
\hline \multicolumn{10}{|l|}{ Access site } \\
\hline Femoral & & 158 & 61 & & & 26 & 59 & & \multirow{2}{*}{$0.511^{\mathrm{x}^{2}}$} \\
\hline Radial & & 100 & 39 & & & 18 & 41 & & \\
\hline Glucose (mg/dL) & $146 \pm 76$ & & & 124 & $160 \pm 86$ & & & 125 & $0.424^{\mathrm{m}}$ \\
\hline Serum creatinine $(\mathrm{mg} / \mathrm{dL})$ & $1.08 \pm 0.32$ & & & 1.01 & $1.13 \pm 0.28$ & & & 1.16 & $0.036^{m}$ \\
\hline Hemoglobin(g/L) & $13.8 \pm 1.8$ & & & 13.8 & $13.7 \pm 1.6$ & & & 13.5 & $0.594^{\mathrm{m}}$ \\
\hline WBC count $\left(x 1000 / \mathrm{mm}^{3}\right)$ & $11.4 \pm 3.8$ & & & 11.1 & $12.0 \pm 4.7$ & & & 11.5 & $0.422^{m}$ \\
\hline Platelet count $\left(x 1000 / \mathrm{mm}^{3}\right)$ & $239 \pm 78$ & & & 231 & $247 \pm 74$ & & & 243 & $0.367^{\mathrm{m}}$ \\
\hline Total cholesterol $(\mathrm{mg} / \mathrm{dL})$ & $187 \pm 45$ & & & 190 & $199 \pm 49$ & & & 199 & $0.095^{m}$ \\
\hline $\mathrm{LDL},(\mathrm{mg} / \mathrm{dL})$ & $116 \pm 38$ & & & 111 & $126 \pm 37$ & & & 122 & $0.082^{m}$ \\
\hline $\mathrm{HDL},(\mathrm{mg} / \mathrm{dL})$ & $39 \pm 11$ & & & 37 & $40 \pm 10$ & & & 39 & $0.383^{m}$ \\
\hline Triglycerides (mg/dL) & $142 \pm 89$ & & & 132 & $154 \pm 95$ & & & 148 & $0.082^{m}$ \\
\hline $\operatorname{LVEF}_{,}(\%)$ & $48 \pm 10$ & & & 50 & $46 \pm 12$ & & & 47 & $0.455^{\mathrm{m}}$ \\
\hline Contrast medium volume $(\mathrm{mL})$ & $210 \pm 50$ & & & 212 & $217 \pm 60$ & & & 223 & $0.105^{m}$ \\
\hline
\end{tabular}

CIN: Contrast-induced nephropathy; SD: Standard deviation; AMI: Acute myocardial infarction; CABG: Coronary artery bypass graft; CAD: Coronary artery disease; DM: Diabetes mellitus; HDL: High-density lipoprotein; HT: Hypertension; LDL: Low-density lipoprotein; LVEF: Left ventricular ejection fraction; TIA: Transient ischemic attack; WBC: White blood cell. mMann-Whitney U Test; $X^{2}$ Chi Square $\left(X^{2}\right)$ Test. 
TABLE 3. The level of native thiol, total thiol, disulfide, and disulfide/total thiol ratio between the patients with and without contrast-induced nephropathy (CIN)

\begin{tabular}{lcccccc} 
& \multicolumn{2}{c}{ CIN $(-)$} & & \multicolumn{2}{c}{ CIN $(+)$} & \\
\cline { 2 - 3 } & Mean \pm SD & Median & & Mean \pm SD & Median & $p$ \\
\hline Total thiol, $(\mu \mathrm{mol} / \mathrm{L})$ & $305.4 \pm 89.7$ & 302.8 & & $260.1 \pm 102.1$ & 263.3 & $0.009^{\mathrm{m}}$ \\
Native thiol $(\mu \mathrm{mol} / \mathrm{L})$ & $274.8 \pm 84.7$ & 282.5 & & $220.8 \pm 97.1$ & 229.1 & $<0.001^{\mathrm{m}}$ \\
Disulfide $(\mu \mathrm{mol} / \mathrm{L})$ & $15.8 \pm 6.6$ & 15.2 & & $19.6 \pm 8.4$ & 18.4 & $0.002^{\mathrm{m}}$ \\
Disulfide/Total thiol $\%, \times 100$ & $5.9 \pm 3.1$ & 5.3 & $8.4 \pm 3.7$ & 8 & $<0.001^{\mathrm{m}}$ \\
\hline
\end{tabular}

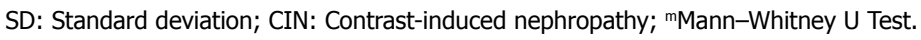

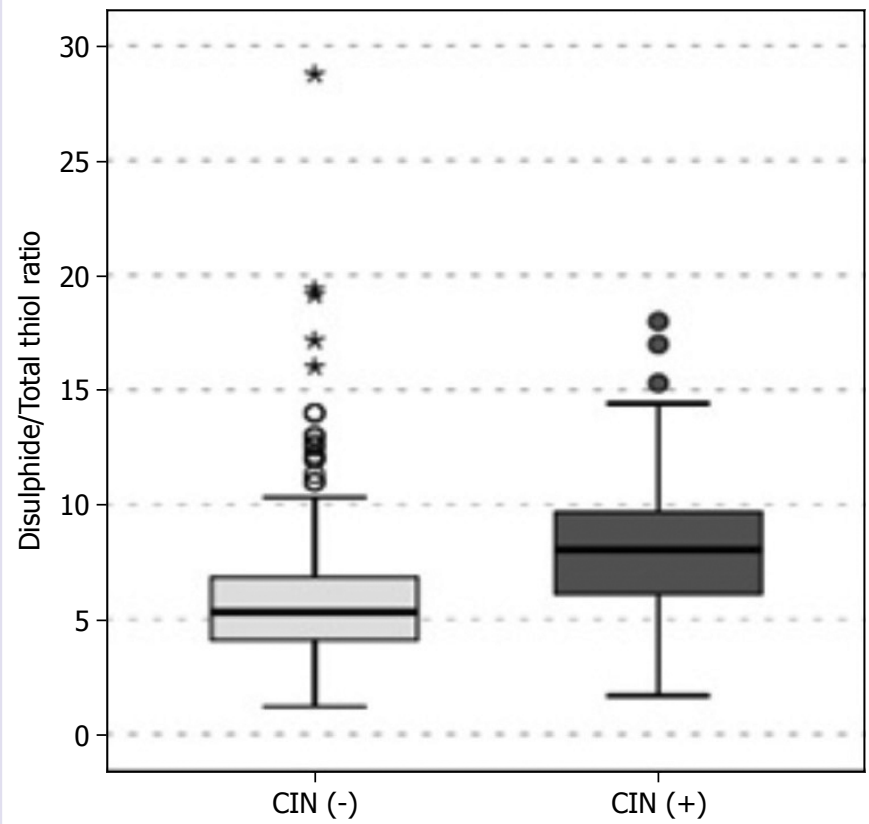

FIGURE 1. Relationship between disulfide total thiol ratio levels with contrast-induced nephropathy in patients with acute myocardial infarction. of ROS and tubular cell toxicity [29, 30]. The plasma thiol/disulfide homeostasis shows a synergistic effect with the contrast media and increases acute kidney injury incidence by increasing ROS levels. Common findings in recent studies on thiol/disulfide levels include decreased native thiol level, increased disulfide level, and increased disulfide/total thiol ratio due to excess oxidative stress $[13,14,18]$. Consistent with previous studies, we found that patients in the CIN $(+)$ group had lower native thiol but a higher disulfide level and disulfide/total thiol ratio as compared to the CIN (-) group.

CIN is closely associated with prolonged hospitalization, increased costs, and increased short- and longterm morbidity and mortality [1]. Various strategies are hence being employed to prevent the incidence of CIN. Recently, increasing evidence has suggested that statins may, aside from their lipid-lowering effect, also play a protective role for the kidneys in the prevention of CIN due to their pleiotropic effects that include anti-inflammatory and antioxidant actions and the enhancement of endothelial nitric oxide production [31,

TABLE 4. Univariate and multivariate logistic regression analysis of contrast-induced nephropathy (CIN)

\begin{tabular}{|c|c|c|c|c|c|c|}
\hline & \multicolumn{3}{|c|}{ Univariate } & \multicolumn{3}{|c|}{ Multivariate } \\
\hline & OR & $\% 95 \mathrm{CI}$ & $\mathrm{p}$ & OR & $\% 95 \mathrm{CI}$ & $\mathrm{p}$ \\
\hline Native thiol & 0.993 & $0.989-0.997$ & $<0.001$ & & & \\
\hline Total thiol & 0.995 & $0.991-0.998$ & 0.003 & & & \\
\hline Disulfide & 1.077 & $1.030-1.126$ & 0.001 & & & \\
\hline Disulfide/Total thiol ratio & 1.199 & $1.098-1.310$ & $<0.001$ & 1.190 & $1.090-1.300$ & $<0.001$ \\
\hline
\end{tabular}

CIN: Contrast-induced nephropathy; OR: Odd ratios; CI: Confidence interval. 


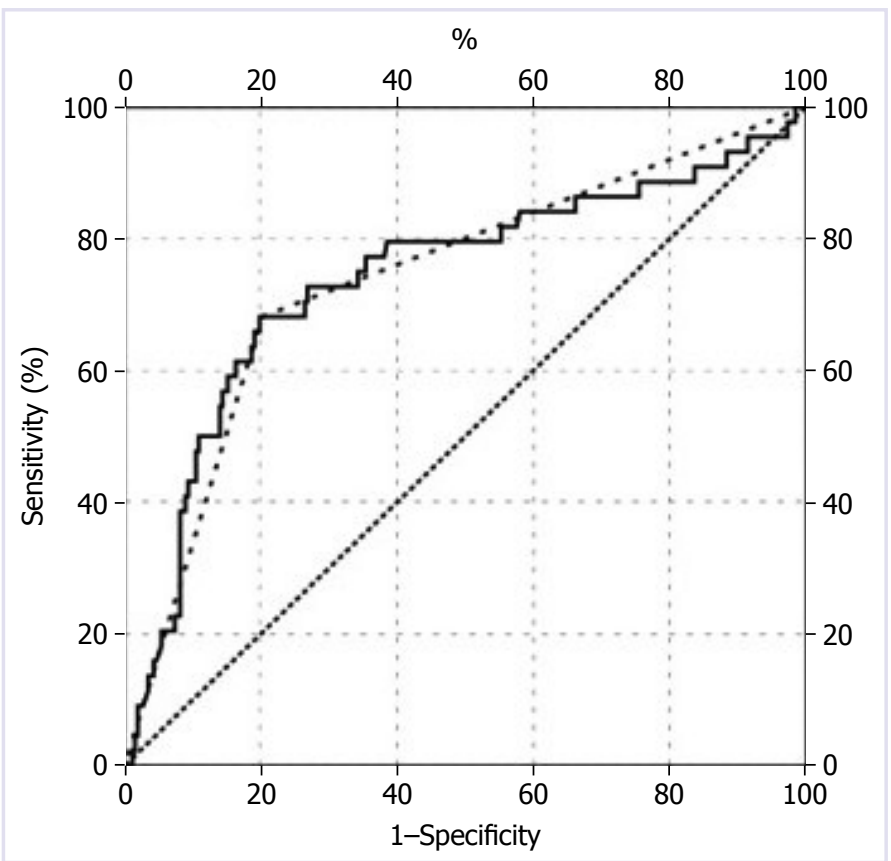

FIGURE2. Receiver operator characteristic (ROC) curve analysis showing that at a cut-off of 7, the value of disulfide total thiol ratio exhibited 68.2 sensitivity and 79.8 specificity for predicting contrast-induced nephropathy.

32]. In other studies involving $\mathrm{N}$-acetylcysteine (NAC), it was demonstrated that the inhibition of reactive oxygen species (ROS) may represent a key mechanism of the nephroprotective effect of NAC $[33,34]$. Based on these findings, we can speculate a relationship between thiol/disulfide homeostasis and CIN.

We suggest that the lower native thiol and higher disulfide level in AMI patients are probably due to an increase in thiol oxidation due to the excess oxidative status during AMI. During the acute phase in AMI, the oxidative response may affect the baseline cardiorenal reserves of the patients. Addition of thiol levels to the current risk models derived from clinical, angiographic, and laboratory-based variables and to the previously validated Mehran risk score [35] may result in significant improvement in the prediction of CIN. This suggests that measurement of thiols improves the evaluation of risk for CIN in patients with STEMI who are undergoing primary $\mathrm{PCI}$.

\section{Study Limitations}

Our study had several limitations. First of all, it included a relatively small number of CIN patients who were admitted to a single center. Secondly, blood samples were obtained at the time of admission, and we did not observe the serial changes in thiols concentration after primary PCI. Thirdly, several novel renal biomarkers, including neutrophil gelatinaseassociated lipocalin, cystatin C, urinary Kim-1, and interleukin 18, were not measured during the study $[36,37]$. Fourthly, because all patients in the present study underwent emergency PCI, the total fluid volume and net fluid balance were not quantified. Moreover, thiols are nonspecific inflammatory and oxidative stress biomarkers that are influenced by cardiac and extra-cardiac conditions. The study group included some patients with diabetes mellitus and potential renal dysfunction, which was another limitation of this study. Finally, the deterioration of renal function after primary PCI may have been caused by multiple other contributing factors, including hemodynamic alterations, neurohormonal activation, and administration of nephrotoxic drugs.

\section{Conclusion}

Our results suggest that thiol/disulfide homeostasis could be a good biochemical risk marker for CIN in STEMI patients who have undergone primary PCI. Considering its clinical significance, thiol/disulfide homeostasis may help in identifying high-risk candidates of CIN in AMI. We believe that larger prospective studies are needed in the future to confirm the pathophysiological role of thiol/disulfide homeostasis in CIN and to provide valuable insights into the relevant literature.

Ethics Committee Approval: The Ethics Committee of SBU Ankara Numune Egitim ve Arastirma Hastanesi provided the ethics committee approval for this study (Date: 22.02.2017 Number: E-16-1096).

Conflict of Interest: The authors have no conflicts of interest to disclose.

Financial Disclosure: The authors declared that this study has received no financial support.

Authorship Contributions: Concept - AKork.; Design - AKork.; Supervision - AKork., AK; Materials - BO, AKork., AK; Data collection and/ or processing - AKork., BO; Analysis and/or interpretation - AKork., UG, MI, OUE; Writing - AKork.; Critical review - UG, SN, OE, OUE, AKork.

\section{REFERENCES}

1. McCullough PA. Contrast-induced acute kidney injury. J Am Coll Cardiol 2008;51:1419-28. [CrossRef]

2. Nash K, Hafeez A, Hou S. Hospital-acquired renal insufficiency. Am J Kidney Dis 2002;39:930-6. [CrossRef] 
3. Mitchell AM, Jones AE, Tumlin JA, Kline JA. Incidence of contrastinduced nephropathy after contrast-enhanced computed tomography in the outpatient setting. Clin J Am Soc Nephrol 2010;5:4-9. [CrossRef]

4. Abe M, Morimoto T, Akao M, Furukawa Y, Nakagawa Y, Shizuta S, et al. Relation of contrast-induced nephropathy to long-term mortality after percutaneouscoronary intervention. Am J Cardiol 2014;114:362-8.

5. Lazaros G, Tsiachris D, Tousoulis D, Patialiakas A, Dimitriadis K, Roussos D, et al. In-hospital worsening renal function is an independent predictor of one-year mortality in patients with acute myocardial infarction. Int J Cardiol 2012;155:97-101. [CrossRef]

6. Sen CK, Packer L. Thiol homeostasis and supplements in physical exercise. Am J Clin Nutr 2000;72:653S-69S. [CrossRef]

7. Turell L, Radi R, Alvarez B. The thiol pool in human plasma: the central contribution of albumin to redoxprocesses. Free Radic Biol Med 2013;65:244-53. [CrossRef]

8. Cremers CM, Jakob U. Oxidant sensing by reversible disulfide bond formation. J Biol Chem 2013;288:26489-96. [CrossRef]

9. Jones DP, Liang Y. Measuring the poise of thiol/disulfide couples in vivo. Free Radic Biol Med 2009;47:1329-38. [CrossRef]

10. Biswas S, Chida AS, Rahman I. Redox modifications of protein-thiols: emerging roles in cell signaling. Biochem Pharmacol 2006;71:551-64.

11. Azzalini L, Spagnoli V, Ly HQ. Contrast-Induced Nephropathy: From Pathophysiology to Preventive Strategies. Can J Cardiol 2016;32:24755. [CrossRef]

12. Ortega LM, Harmouch I, Nayer A. Contrast-induced nephropathy: pathogenesis and new therapeutic options for prevention. Am J Ther 2015;22:469-76. [CrossRef]

13. Kundi H, Ates I, Kiziltunc E, Cetin M, Cicekcioglu H, Neselioglu S, et al. A novel oxidative stress marker in acute myocardial infarction; thiol/ disulphide homeostasis. Am J Emerg Med 2015;33:1567-71. [CrossRef]

14. Kundi H, Erel Ö, Balun A, Çiçekçioğlu H, Cetin M, Kiziltunç E, et al. Association of thiol/disulfide ratio with syntax score in patients with NSTEMI. Scand Cardiovasc J 2015;49:95-100. [CrossRef]

15. Ibanez B, James S, Agewall S, Antunes MJ, Bucciarelli-Ducci C, Bueno H, et al. 2017 ESC Guidelines for the management of acute myocardial infarction in patients presenting with ST-segment elevation: The Task Force for the management of acute myocardial infarction in patients presenting with ST-segment elevation of the European Society of Cardiology (ESC). Eur Heart J 2018;39:119-77. [CrossRef]

16. Lazaros G, Tsiachris D, Vlachopoulos C, Chrysohoou C, Milkas A, Papageorgiou $\mathrm{N}$, et al. Distinct association of admission hyperglycemia with one-year adverse outcome in diabetic and non-diabetic patients with acute ST-elevation myocardial infarction. Hellenic J Cardiol 2013;54:119-25.

17. Erel O, Neselioglu S. A novel and automated assay for thiol/disulphide homeostasis. Clin Biochem 2014;47:326-32. [CrossRef]

18. Topuz M, Kaplan M, Akkus O, Sen O, Yunsel HD, Allahverdiyev $\mathrm{S}$, et al. The prognostic importance of thiol/disulfide homeostasis in patients with acute pulmonary thromboembolism. Am J Emerg Med 2016;34:2315-9. [CrossRef]

19. Kızıltunç E, Gök M, Kundi H, Çetin M, Topçuoğlu C, Gülkan B, et al. Plasma thiols and thiol-disulfide homeostasis in patients with isolated coronary artery ectasia. Atherosclerosis 2016;253:209-13. [CrossRef]

20. Altıparmak IH, Erkuş ME, Sezen H, Demirbag R, Gunebakmaz O,
Kaya Z, et al. The relation of serum thiol levels and thiol/disulphide homeostasis with the severity of coronary artery disease. Kardiol Pol 2016;74:1346-53. [CrossRef]

21. Topuz M, Şen O, Kaplan M, Akkus O, Erel O, Gur M. The Role of Thiol/Disulphide Homeostasis in Anthracycline Associated Cardiac Toxicity. Int Heart J 2017;58:69-72. [CrossRef]

22. Börekçi A, Gür M, Türkoğlu C, Çaylı M, Selek Ş, Kaypaklı O, et al. Oxidative stress and paraoxonase 1 activity predict contrast-induced nephropathy in patients with ST-segment elevation myocardial infarction undergoing primary percutaneous coronary intervention. Angiology 2015;66:339-45. [CrossRef]

23. Jian-Wei Z, Yu-Jie Z, Shu-Jun C, Qing Y, Shi-Wei Y, Bin N. Impact of preprocedural high-sensitivity $\mathrm{C}$-reactive protein on contrast-inducednephropathy in patients undergoing primary percutaneous coronary intervention. Angiology 2014;65:402-7. [CrossRef]

24. Kurtul A, Duran M, Yarlioglues M, Murat SN, Demircelik MB, Ergun $\mathrm{G}$, et al. Association between $\mathrm{N}$-terminal pro-brain natriuretic peptide levels and contrast-induced nephropathy in patients undergoing percutaneous coronary intervention for acute coronary syndrome. Clin Cardiol 2014;37:485-92. [CrossRef]

25. Huang SS, Huang PH, Wu TC, Chen JW, Lin SJ. Association of serum bilirubin with contrast-induced nephropathy and future cardiovascular events in patients undergoing coronary intervention. PLoS One 2012;7:e42594. [CrossRef]

26. Elbasan Z, Şahin DY, Gür M, Kuloğlu O, Kivrak A, Içen YK, et al. Contrast-induced nephropathy in patients with ST elevation myocardial infarction treated with primary percutaneous coronary intervention. Angiology 2014;65:37-42. [CrossRef]

27. Oksuz F, Yarlioglues M, Cay S, Celik IE, Mendi MA, Kurtul A, et al. Predictive Value of Gamma-Glutamyl Transferase Levels for ContrastInduced Nephropathy in Patients With ST-Segment Elevation Myocardial Infarction Who Underwent Primary Percutaneous Coronary Intervention. Am J Cardiol 2015;116:711-6. [CrossRef]

28. Solomon R, Dauerman HL. Contrast-induced acute kidney injury. Circulation 2010;122:2451-5. [CrossRef]

29. McCullough PA, Adam A, Becker CR, Davidson C, Lameire N, Stacul F, et al; CIN Consensus Working Panel. Risk prediction of contrastinduced nephropathy. Am J Cardiol 2006;98:27K-36K. [CrossRef]

30. Persson PB, Tepel M. Contrast medium-induced nephropathy: the pathophysiology. Kidney Int Suppl 2006:S8-10. [CrossRef]

31. Zografos TA, Oikonomou E, Siasos G, Mourouzis K, Dimitropoulos E, Antonopoulos A, et al. High-Dose Statin Therapy Is Effective At Preventing The Development Of Contrast-Induced Nephropathy In Patients Undergoing Percutaneous Coronary Intervention For Acute Coronary Syndromes: A Meta-Analysis. JACC 2016;67. [CrossRef]

32. Toso A, Leoncini M, Maioli M, Tropeano F, Di Vincenzo E, Villani S, et al. Relationship between inflammation and benefits of early high-dose rosuvastatin on contrast-induced nephropathy in patients with acute coronary syndrome: the pathophysiological link in the PRATO-ACS study (Protective Effect of Rosuvastatin and Antiplatelet Therapy on Contrast-Induced Nephropathy and Myocardial Damage in Patients With Acute Coronary Syndrome Undergoing Coronary Intervention). JACC Cardiovasc Interv 2014;7:1421-9. [CrossRef]

33. Trivedi H, Daram S, Szabo A, Bartorelli AL, Marenzi G. High-dose 
$\mathrm{N}$-acetylcysteine for the prevention of contrast-induced nephropathy. Am J Med 2009;122:874.e9-15. [CrossRef]

34. Kang X, Hu DY, Li CB, Ai ZS, Peng A. N-acetylcysteine for the prevention of contrast-induced nephropathy in patients with pre-existing renal insufficiency or diabetes: a systematic review and meta-analysis. Ren Fail 2015;37:297-303. [CrossRef]

35. Mehran R, Aymong ED, Nikolsky E, Lasic Z, Iakovou I, Fahy M, et al. A simple risk score for prediction of contrast-induced nephropathy after percutaneous coronary intervention: development and initial vali- dation. J Am Coll Cardiol 2004;44:1393-9. [CrossRef]

36. Alharazy SM, Kong N, Saidin R, Gafor AH, Maskon O, Mohd M, et al. Serum neutrophil gelatinase-associated lipocalin and cystatin $\mathrm{C}$ are early biomarkers of contrast-induced nephropathy after coronary angiography in patients with chronic kidney disease. Angiology 2014;65:436-42. [CrossRef]

37. Duan SB, Liu GL, Yu ZQ, Pan P. Urinary KIM-1, IL-18 and Cys-c as early predictive biomarkers in gadolinium-based contrast-induced nephropathy in the elderly patients. Clin Nephrol 2013;80:349-54. 